\title{
Temporal trends and inequality in under-5 mortality from diarrea
}

\author{
LÍGIA C. F. L. MELLI 1, ELISEU A. WALKMAN 2
}

1. Mestre, Centro Universitário FIEO (UNIFIEO), Osasco, SP, Brazil.

2. Doutor, Faculdade de Saúde Pública, Universidade de São Paulo (USP), São Paulo, SP, Brazil.

\begin{abstract}
Objective: To analyze the trend in mortality due to diarrhea among children under 5 in the town of Osasco (SP), Brazil, between 1980 and 2000. Methods: This is a descriptive observational study with two different designs, the first using individuals as the unit of study, and the other ecological, using groups of individuals as units of observation and including time series analysis. Data were obtained from the state of São Paulo information system of deaths and the results of the 1980, 1991 and 2000 censuses. Seasonal variations were described and log linear polynomial regression models were employed to analyze trends, using the sociodemographic characteristics of mothers and their children. Analyses were carried out of the changes in the town's sociodemographic indicators from 1980 to 2000, the average mortality rates among under-5s due to diarrhea and the differences between districts during the 1990s. Results: There were a total of 1,360 deaths, $94.3 \%$ of which were before 1 year of age and $75.3 \%$ of which were before 6 months. There was a 98.3\% reduction in mortality and the period of peak mortality shifted from summer to autumn/fall. The median age at death increased from 2 months at the first three quinquenium of study to 3 months at the last. The residual deaths were among the children of mothers aged 20 to 29 years and of mothers who had spent less than 8 years in education. The relative risk between the worst-affected district and the average rate for the town reduced from 3.4 to 1.3 from the first 5 years of the 1990s to the second half of the decade. Conclusions: Our results demonstrate an increase in the age of greatest vulnerability and indicate that it is probable that the agent most often linked with mortality due to diarrhea has changed.
\end{abstract}

(Key words: Diarrhea, infant mortality, time-series, social indicators, economic indicators). J Pediatr (Rio J). 2009;85(1):21-27

ESTE TRABAJO LO PUEDE ENCONTRAR EN EXTENSO EN WWW.SciELO.ORG

Correspondencia a:

Lígia Cristina Fonseca Lahoz Melli

E-mail: Imelli@uol.com.br 